\title{
A comparative study of water soluble 5,10,15,20-tetrakis(2,6- dichloro-3-sulfophenyl)porphyrin and its metal complexes as efficient sensitizers for photodegradation of phenols
}

\author{
Carlos J. P. Monteiro, ${ }^{a}$ Mariette M. Pereira, ${ }^{* a}$ M. Emilia Azenha, ${ }^{* a}$ Hugh D. Burrows, ${ }^{a}$ \\ Carlos Serpa, ${ }^{a}$ Luis G. Arnaut, ${ }^{a}$ M. J. Tapia, ${ }^{b}$ Mohamed Sarakha, ${ }^{c}$ Pascal Wong-Wah-Chung ${ }^{c}$ \\ and Suppiah Navaratnam ${ }^{d, e}$ \\ a Departamento de Química, Universidade de Coimbra, 3004-535, Coimbra, Portugal. \\ E-mail: mmpereira@qui.uc.pt; Fax: +351+239+827703; Tel: +351+239+854474 \\ ${ }^{b}$ Departamento de Química, Universidad de Burgos, Plaza Misael Bañuelos, Burgos, 09001, \\ Spain \\ ${ }^{c}$ Laboratoire de Photochimie Moléculaire et Macromoléculaire, UMR CNRS 433, \\ Université Blaise-Pascal, Clermont Ferrand, 63177, Aubière Cedex, France \\ ${ }^{d}$ Free Radical Research Facility, Daresbury Laboratory, Warrington, UK WA4 4AD \\ ${ }^{e}$ Biosciences Research Institute, University of Salford, UK M4 4WT
}

Received 31st May 2005, Accepted 9th June 2005

First published as an Advance Article on the web 28th June 2005

\begin{abstract}
5,10,15,20-Tetrakis(2,6-dichloro-3-chlorosulfophenyl)porphyrin and its tin and zinc complexes were synthesized with high yields and fully characterized. The corresponding water-soluble 5,10,15,20-tetrakis(2,6-dichloro-3sulfophenyl)porphyrins were obtained by hydrolysis with water. An extensive photophysical study of the new water soluble porphyrinic compounds was carried out including absorption and fluorescence spectra, fluorescence quantum yields, triplet absorption spectra, triplet lifetimes, triplet and singlet oxygen quantum yields. These sensitizers were successfully used in the photodegradation of 4-chlorophenol and 2,6-dimethylphenol. A comparison is made of their efficiencies, and some mechanistic considerations are highlighted.
\end{abstract}

\section{Introduction}

Phenols are major pollutants. Particular concern has been expressed on chlorophenols which are widely used as fungicides, herbicides, wood-protection agents and are also produced in the Kraft bleaching of paper pulp. ${ }^{1}$ In addition, other substituted phenols also have negative environmental effects, and serious concerns have been expressed about the levels of these compounds in waste and groundwater. Several methods have been employed to degrade these pollutants. ${ }^{2-6}$ Photooxidation appears to be particularly valuable, ${ }^{7}$ and in the last decade much effort has been devoted to the development of new and clean sensitizers that use visible light to degrade these compounds to readily biodegradable photoproducts. ${ }^{8-10}$ Degradation studies of phenols in the presence of different singlet oxygen sensitizers have been reported, and provide important mechanistic information. ${ }^{11-13}$ For optimum efficiency, photosensitizers should have as broad UV/visible absorption bands as possible. Porphyrins and phthalocyanines have strong visible absorptions ${ }^{14}$ and are particularly good candidates for such photooxidation of phenols. ${ }^{15-17}$ Triplet states of these sensitizers are implicated, with reactions going via both Type I and Type II mechanisms. ${ }^{18}$

$$
\text { Sens }+h v \rightarrow{ }^{1} \text { Sens } * \rightarrow{ }^{3} \text { Sens* }
$$

Type I mechanism

$$
{ }^{3} \text { Sens } *+\mathrm{ClPhOH} \rightarrow \text { radical products }
$$

Type II mechanism

$$
\begin{aligned}
& { }^{3} \text { Sens } *+\mathrm{O}_{2} \rightarrow \text { Sens }+{ }^{1} \mathrm{O}_{2} * \\
& { }^{1} \mathrm{O}_{2}{ }^{*}+\mathrm{ClPhOH} \rightarrow \text { products }
\end{aligned}
$$

The heavy atom effect induced by the presence of chlorine makes 5,10,15,20-tetrakis(2,6-dichlorophenyl)porphyrin and its metal derivatives particularly good photosensitizers for singlet oxygen production ${ }^{19-21}$ as shown by their use as photooxidants of phenols and naphthols. ${ }^{22}$ For applications in waste water treatment, soluble derivatives, such as the 3 -sulfophenyl salts, are particularly valuable, and we have shown that iron 5,10,15,20tetrakis(2,6-dichloro-3-sulfophenyl)porphyrin is a powerful sensitizer for the photooxidation of 4-chlorophenol. ${ }^{17}$ The products depend on the presence or absence of oxygen, with the reaction involving both Type I and Type II mechanisms.

To test the role of the metal on these processes, we have extended the study to the free base of this water soluble porphyrin, $\mathbf{1}$, and to the newly synthesized zinc, $\mathbf{2}$, and tin, $\mathbf{3}$, derivatives. Relevant photophysical parameters are presented, reaction products, kinetics and mechanistic details of the photosensitized degradation of 4-chlorophenol (4-CP) and 2,6dimethylphenol (2,6-DMP) are reported.

\section{Experimental}

\subsection{Chemicals}

4-Chlorophenol (4-CP) (Aldrich) p-benzoquinone (BQ) (Aldrich Chem p.a.), p-hydroquinone (HQ) (Merck p.a.), 2,6dimethylphenol (2,6-DMP) (Aldrich), sodium azide $\left(\mathrm{NaN}_{3}\right)$, dimethylthiourea (Aldrich) and methanol (HPLC analysis grade, Merck) were used as received. 2,6-Dimethylbenzoquinone (2,6-DBQ) was synthesized using a literature method. ${ }^{5}$ All solvents used in the synthesis of the photosensitizer were purified before use. Solutions were prepared with doubly distilled water, either equilibrated with air or bubbled with nitrogen for $30 \mathrm{~min}$ at room temperature. 


\subsection{Porphyrin and metalloporphyrin synthesis}

The synthesis of 5,10,15,20-tetrakis(2,6-dichlorophenyl)porphyrin and 5,10,15,20-tetrakis(phenyl)porphyrin (TPP) has been described elsewhere. ${ }^{23}$ 5,10,15,20-Tetrakis(2,6-dichloro3-sulfophenyl)porphyrin (1) was synthesized according to our previously described method ${ }^{17,23}$ (Scheme 1).

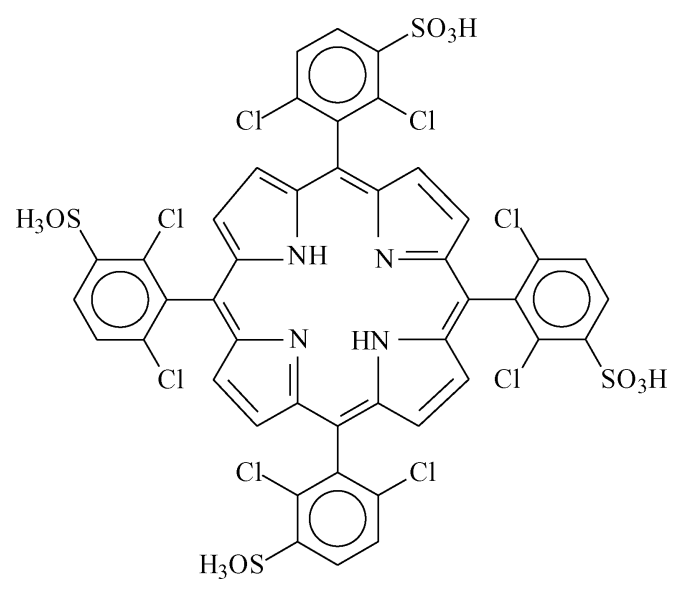

Scheme 1

\section{5,10,15,20-Tetrakis(2,6-dichloro-3-sulfophenyl)porphyrin.}

Analysis. Calcd. for $\mathrm{C}_{44} \mathrm{H}_{18} \mathrm{~N}_{4} \mathrm{O}_{8} \mathrm{Cl}_{12} \mathrm{~S}_{4}: \mathrm{C}, 41.1 ; \mathrm{H}, 1.4 ; \mathrm{N}, 4.4$. Found: C, 40.7; H, 1.6; N, 4.3. MS (FAB), $\left[\mathrm{M}^{+}\right] 1279 .{ }^{1} \mathrm{H}$ NMR $\left(\mathrm{CDCl}_{3}\right),(\delta: 8.64(8 \mathrm{H}, \mathrm{s}) ; 8.59(4 \mathrm{H}, \mathrm{d}, J=8.6 \mathrm{~Hz}) ; 8.05(4 \mathrm{H}$, d, $J=8.6 \mathrm{~Hz}) ;-2.35,(2 \mathrm{H}, \mathrm{s})$.

\section{Preparation of metal complexes.}

5,10,15,20-Tetrakis(2,6-dichloro-3-chlorosulfophenyl) porphyrinate $\mathrm{Zn}(\mathrm{II})$. 5,10,15,20-Tetrakis (2,6-dichloro-3-chlorosulfophenyl)porphyrinate $\mathrm{Zn}$ (II) was prepared according to the method of Adler and co-workers. ${ }^{24}$ 5,10,15,20-Tetrakis(2,6dichloro-3-chlorosulfophenyl)porphyrin $(50 \mathrm{mg}$; $0.039 \mathrm{mmol})$, zinc(II) acetate $(0.043 \mathrm{~g} ; 0.195 \mathrm{mmol})$ in $N, N$-dimethylformamide $(15 \mathrm{~mL})$ were stirred at $150{ }^{\circ} \mathrm{C}$ for $4 \mathrm{~h}$. The reaction was monitored by UV-visible spectroscopy until the $4 \mathrm{Q}$ bands are transformed into the $2 \mathrm{Q}$ bands typical of the corresponding porphyrin metal complexes. After solvent evaporation the residue was extracted with chloroform and washed (3 times) with water. The solution was dried with $\mathrm{MgSO}_{4}$ and evaporated. The solid was dried, yielding 5,10,15,20-tetrakis(2,6-dichloro3-chlorosulfophenyl)porphyrinate $\mathrm{Zn}$ (II) $(48 \mathrm{mg}, 0.035 \mathrm{mmol}$, $90 \%) .{ }^{1} \mathrm{H}$ NMR $\left(\mathrm{CDCl}_{3}\right), \delta: 8.62(8 \mathrm{H}, \mathrm{s}) ; 8.57(4 \mathrm{H}, \mathrm{d}, J=$ $8.6 \mathrm{~Hz}) ; 8.03(4 \mathrm{H}, \mathrm{d}, J=8.6 \mathrm{~Hz})$.

5,10,15,20-Tetrakis(2,6-dichloro-3-chlorosulfophenyl) porphyrinate $\mathrm{Sn}(\mathrm{IV})$ chloride. 5,10,15,20-Tetrakis (2,6-dichloro-3chlorosulfophenyl)porphyrinate $\mathrm{Sn}$ (IV) was prepared according to the method of Whitten and co-workers. ${ }^{25}$ For this, 5,10,15,20tetrakis(2,6-dichloro-3-chlorosulfophenyl)porphyrin (50 $\mathrm{mg}$; $0.039 \mathrm{mmol})$, tin(II) chloride $(0.044 \mathrm{~g} ; 0.195 \mathrm{mmol})$ were dissolved in pyridine $(15 \mathrm{~mL})$ and stirred at $150{ }^{\circ} \mathrm{C}$ for $10 \mathrm{~h}$ in nitrogen atmosphere. The reaction was monitored by
UV/visible spectroscopy until the 4 Q bands are transformed into the $2 \mathrm{Q}$ bands typical of porphyrin metal complexes. Finally, the reaction was stirred in contact with air for $4 \mathrm{~h}$ to promote the oxidation from $\mathrm{Sn}(\mathrm{II})$ to $\mathrm{Sn}$ (IV). After solvent evaporation the residue was extracted with chloroform and washed (3 times) with water. The solution was dried with $\mathrm{MgSO}_{4}$ and evaporated. The solid was dried, yielding 5,10,15,20-tetrakis(2,6-dichloro3-chlorosulfophenyl)porphyrinate $\mathrm{Sn}$ (II) chloride (46 mg, $0.033 \mathrm{mmol}, 85 \%)$. ${ }^{1} \mathrm{H}$ NMR $\left(\mathrm{CDCl}_{3}\right), \delta: 8.88(8 \mathrm{H}, \mathrm{s}) ; 8.63$ (4 H, d, $J=7.2 \mathrm{~Hz}) ; 8.07$ (4 H, d, $J=7.2 \mathrm{~Hz})$.

General method for hydrolysis of chlorosulfonyl compounds to sulfonic acids. Suspensions of the above chlorosulfonated porphyrin or metalloporphyrins $(80 \mathrm{mg})$ in water were refluxed for $12 \mathrm{~h}$. The resulting solution was concentrated by rotary evaporation and purified using an AMICON-Stirred Ultrafiltration Cell (model 8200). After filtration (3 times) the solutions were concentrated by evaporation and the sulfonic acid porphyrin derivatives precipitated with acetone. The required solids 5,10,15,20-tetrakis(2,6-dichloro-3-sulfophenyl)porphyrin (TDCPPS, 1), 5,10,15,20-tetrakis (2,6-dichloro-3sulfophenyl)porphyrinate $\mathrm{Zn}(\mathrm{II})$ (ZnTDCPPS 2), and 5,10, 15,20-tetrakis (2,6-dichloro-3-sulfophenyl)porphyrinate Sn(IV) chloride (SnTDCPPS, 3) were isolated by filtration and dried at $100{ }^{\circ} \mathrm{C}$, yielding 90,89 , and $90 \%$, respectively.

5,10,15,20-Tetrakis(2,6-dichloro-3-sulfophenyl)porphyrin, 1. ${ }^{1} \mathrm{H}$ NMR $\left(\mathrm{CD}_{3} \mathrm{OD}\right), \delta: 8.6-9.0(8 \mathrm{H}, \mathrm{m}) ; 8.30-8.50(4 \mathrm{H}, \mathrm{m})$; 7.90-8.05 (4 H, m); -2.35, (2 H, s).

5,10,15,20-Tetrakis (2,6-dichloro-3-sulfophenyl) porphyrinate $\mathrm{Zn}(\mathrm{II}), 2 .{ }^{1} \mathrm{H}$ NMR $\left(\mathrm{CD}_{3} \mathrm{OD}\right), \delta: 8.68-9.0(8 \mathrm{H}, \mathrm{m}) ; 8.53(4 \mathrm{H}$, $\mathrm{d}, J=8.4 \mathrm{~Hz}) ; 8.03(4 \mathrm{H}, \mathrm{d}, J=8.4 \mathrm{~Hz})$.

5,10,15,20-Tetrakis (2,6-dichloro-3-sulfophenyl) porphyrinate $\mathrm{Sn}(\mathrm{IV})$ chloride, 3. ${ }^{1} \mathrm{H} \mathrm{NMR}\left(\mathrm{CD}_{3} \mathrm{OD}\right), \delta: 8.87-8.89(8 \mathrm{H}, \mathrm{m})$; $8.63(4 \mathrm{H}, \mathrm{d}, J=7.5 \mathrm{~Hz}) ; 8.03(4 \mathrm{H}, \mathrm{d}, J=7.5 \mathrm{~Hz})$.

Photophysical data for all the above compounds are presented in Table 1.

\subsection{Equipment}

${ }^{1} \mathrm{H}$ NMR spectra were recorded on a $300 \mathrm{MHz}$ BruckerAMX. Mass spectra were obtained through the MS services of the University of Aveiro (Portugal) and University of Wales, Swansea. UV-visible absorption spectra were recorded in quartz cells on a Shimadzu 2100 spectrometer. The molar absorption coefficients were determined using buffered aqueous solutions $\left(\mathrm{KH}_{2} \mathrm{PO}_{4}-\mathrm{NaOH}, \mathrm{pH}\right.$ 7.4).

The fluorescence measurements were made with a SPEX Fluorolog 3-22 spectrofluorimeter, equipped with a $300 \mathrm{~W}$ xenon lamp as excitation source. Fluorescence quantum yields were determined for deaerated aqueous solutions of the porphyrins. $5,10,15,20$-Tetrakisphenylporphyrin (TPP) in toluene was used as fluorescence standard $\left(\Phi_{\mathrm{F}}=0.11\right)^{26}$ for the determination of the fluorescence quantum yield of TPPS. This was calculated by comparing its spectrally integrated emission to that of the reference solution after correction for the difference in refractive index of toluene and water $\left(\eta_{\text {toluene }}=1.49693\right.$ and $\eta_{\text {water }}=$ 1.332988). ${ }^{27}$ The fluorescence quantum yields of the sensitizers $\mathbf{1}$, $\mathbf{2}$ and $\mathbf{3}$ in deaerated solutions in water were measured relative to

Table 1 Absorption and fluorescence bands, lowest excited singlet energies $\left(E_{\mathrm{s}}\right)$ and fluorescence quantum yields of sensitizers $\mathbf{1}, \mathbf{2}$ and $\mathbf{3}$ in aqueous buffer solution ( $\mathrm{pH} 7.4)$

\begin{tabular}{|c|c|c|c|c|c|c|c|c|c|}
\hline \multirow{2}{*}{ Porph. } & \multicolumn{5}{|c|}{ Absorption $\lambda_{\max } / \mathrm{nm}\left(\varepsilon / \mathrm{M}^{-1} \mathrm{~cm}^{-1}\right)$} & \multicolumn{2}{|c|}{$\begin{array}{l}\text { Fluorescence } \\
\lambda_{\max } / \mathrm{nm} 25^{\circ} \mathrm{C}\end{array}$} & \multirow{2}{*}{$E_{\mathrm{s}} / \mathrm{kJ} \mathrm{mol}^{-1}$} & \multirow{2}{*}{$\Phi_{\mathrm{F}}$ (degassed) } \\
\hline & $\mathrm{Q}_{x}(0-0)$ & $\mathrm{Q}_{x}(1-0)$ & $\mathrm{Q}_{y}(0-0)$ & $\mathrm{Q}_{y}(1-0)$ & $\mathrm{B}(0-0)$ & $\mathrm{Q}(0-0)$ & $\mathrm{Q}(0-1)$ & & \\
\hline $\mathrm{TPPS}_{4}$ & $634(1100)$ & $554(3100)$ & $578(2400)$ & $518(5800)$ & $413\left(2 \times 10^{5}\right)$ & 641 & 697 & 187.6 & $5.4 \times 10^{-2}$ \\
\hline TDCPPS, 1 & $640(380)$ & $584(1800)$ & $554(860)$ & $517(4500)$ & $416\left(1 \times 10^{5}\right)$ & 643 & 704 & 186.5 & $1.3 \times 10^{-3}$ \\
\hline ZnTDCPPS, 2 & $610(1200)$ & $558(5600)$ & - & - & $424\left(1.4 \times 10^{5}\right)$ & 612 & 658 & 195.8 & $3.5 \times 10^{-3}$ \\
\hline SnTDCPPS, 3 & $592(470)$ & $556(4900)$ & $516(1400)$ & - & $420\left(1.2 \times 10^{5}\right)$ & 624 & 649 & 196.9 & $1.5 \times 10^{-3}$ \\
\hline
\end{tabular}


that of TPPS All the solutions were adjusted to 0.02 absorbance at the Soret band.

The transient absorption spectra were measured with an Applied Photophysics LKS 60 nanosecond laser flash photolysis kinetic spectrometer, using the third harmonic $(355 \mathrm{~nm})$ of a Spectra-Physics Quanta Ray GCR 130-01 Nd:YAG laser for excitation, a Hamamatsu 1P28 photomultiplier and a HewlettPackard Infinium oscilloscope (1 GS $\left.\mathrm{s}^{-1}\right)$. Flash photolysis triplet lifetime measurements were made on aerated and argon saturated solutions $\left(\mathrm{ca} .1 \times 10^{-5} \mathrm{M}\right)$, with an absorbance of 0.20 at the excitation wavelength. The triplet-triplet absorption at $460 \mathrm{~nm}$ was used for lifetime measurements. All the decays gave good monoexponential fits. The effect of oxygen as quencher of the triplet state of the photosensitizers $\mathbf{1}-\mathbf{3}$ in aqueous solutions was studied in air-equilibrated $\left(\left[\mathrm{O}_{2}\right]=2.9 \times 10^{-4} \mathrm{M}\right)^{27}$ and deaerated solutions. The effect of 4-CP as a quencher of the excited state of the photosensitizers 1-3 was studied in deaerated solutions.

Room-temperature singlet-oxygen phosphorescence was measured by two independent methods, both using excitation by the third harmonic $(355 \mathrm{~nm})$ of a Nd:YAG laser. The absorbance of the sensitizers was adjusted to 0.20 at the excitation wavelength, under conditions such that there were no indications of aggregation of the porphyrins. For the studies carried out in Coimbra, the singlet oxygen emission at $1270 \mathrm{~nm}$ was detected by a Hamamatsu R5509-42 photomultiplier, cooled to $193 \mathrm{~K}$ in a liquid nitrogen chamber (Products for Research model PC176TSCE005), following laser excitation of aerated $\mathrm{D}_{2} \mathrm{O}$ solutions using an adapted Applied Photophysics flash kinetic spectrometer, which allows for the spectral identification of the singlet oxygen phosphorescence and for the measurement of its lifetime in the nanosecond and microsecond range. The modification of the spectrometer involved the interposition of a Melles Griot dielectric mirror (08MLQ005/345), that reflects more than $99.5 \%$ of the incident light in the $610-860 \mathrm{~nm}$ range, and a Scotch RG665 filter. A 600 line diffraction grating was mounted in the place of the standard diffraction grating of the spectrometer. The filters employed are essential to eliminate from the infrared signal all the first harmonic contributions from the sensitizer emission in the $500-800 \mathrm{~nm}$. To validate this technique, singlet oxygen $\left({ }^{1} \Delta_{\mathrm{g}}\right)$ yields and lifetimes were also obtained at Daresbury using a liquid nitrogen cooled Applied Detector Corporation 403HS Germanium Detector-Amplifier close-coupled to a laser photolysis cell in right-angle geometry. A $1 \mathrm{~mm}$ thick, $20 \mathrm{~mm}$ diameter piece of AR-coated silicon (IIIV Inc) was placed between the diode and cell to act as cut-off filter below $1100 \mathrm{~nm}$. The 403HS power supply bias voltage was operated at $450 \mathrm{~V}$. The amplifier output was AC coupled to a transient digitizer, as described in detail elsewhere. ${ }^{28-30}$ The quantum yield of singlet oxygen formation was determined by comparison of the initial emission intensity for optically matched solutions at the excitation wavelength of $532 \mathrm{~nm}$ using TPPS in $\mathrm{D}_{2} \mathrm{O}\left(A_{532}=0.20 ; \cong 10^{-5} \mathrm{M}, \Phi_{\Delta}=0.64\right)^{31}$ as standard. A reasonable agreement was obtained between the singlet oxygen yields using the two experimental set-ups.

Measurements of triplet yields were carried out by laser flash photolysis on aqueous porphyrin solutions $\left(7 \times 10^{-6} \mathrm{M}\right)$ at $\mathrm{pH} 7.4$ using the $355 \mathrm{~nm}$ line of a Nd:YAG laser. Triplet state extinction coefficients $\left(\varepsilon_{\mathrm{T}}\right)$ were calculated by the singlet depletion method..$^{48}$ Triplet formation quantum yields $\left(\Phi_{\mathrm{T}}\right)$ were obtained by the comparative technique using TPPS as standard $\left(\varepsilon_{\mathrm{T}}=6.5 \times 10^{4} \mathrm{M}^{-1} \mathrm{~cm}^{-1}\right.$ at $\left.460 \mathrm{~nm}, \Phi_{\mathrm{T}}=0.61\right){ }^{38,48,49}$

Continuous irradiation at $350 \mathrm{~nm}$ of aerated solutions of sensitizers 1, 2 and 3, with 4-CP was carried out using a semimicroreactor, equipped with a mercury lamp. The reaction was monitored both by UV-visible spectroscopy and HPLC analysis. The $\mathrm{pH}$ was monitored throughout the irradiation time using a Crison micro-pH 2000 apparatus. For mechanistic studies, an aerated solution of photosensitizer $1\left(10^{-4} \mathrm{M}\right)$ and 4-CP $(5 \times$ $10^{-4} \mathrm{M}$ ) was irradiated at $350 \mathrm{~nm}$ in the presence of sodium azide $\left(10^{-3} \mathrm{M}\right)$ or thiourea $\left(10^{-3} \mathrm{M}\right)$. In the case of 2,6-dimethylphenol $\left(2 \times 10^{-4} \mathrm{M}\right)$, the determination of the quantum yields at $415 \mathrm{~nm}$ was carried out by using a parallel beam obtained from a Schoeffel monochromator connected to a xenon lamp (1600 W). The reactor was a quartz cell of $1 \mathrm{~cm}$ path length. The photon flux was evaluated by means of classical ferrioxalate actinometry. ${ }^{32}$

The photostability of the sensitizer and 4-CP or 2,6-DMP was studied. The analysis of degradation products was made using HPLC with an Agilent Technologies chromatography system equipped with a UV-visible 1100 Series variable wavelength detector, G1314 A0 and 1100 Iso pump, G1310-64001, with detection set at $280 \mathrm{~nm}$. A reverse phase column (Zorbax ODS, $4.6 \mathrm{~mm} \times 250 \mathrm{~mm}, 5 \mu \mathrm{m})$ was used with a mixture of $\mathrm{MeOH}-$ $\mathrm{H}_{2} \mathrm{O}(60: 40 \mathrm{v} / \mathrm{v})$ as eluent, in isocratic mode with a flow rate of $1 \mathrm{~mL} \mathrm{~min}^{-1}$. In the case of 2,6-DMP, the kinetic degradation was followed by using a Hewlett-Packard Liquid Chromatography system (HP1050) equipped with a mono-channel UV-visible detector and an automatic injector. The experiments were performed using a reverse phase Merck column (Spherisorb ODS-2, $4.6 \mathrm{~mm} \times 250 \mathrm{~mm}, 5 \mu \mathrm{m})$ and UV detection at $280 \mathrm{~nm}$.

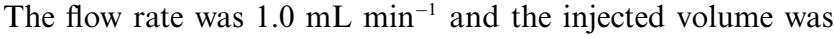
$50 \mu \mathrm{L}$. The elution was accomplished with water with acetic acid $(0.1 \%)$ and acetonitrile $(60: 40 \mathrm{v} / \mathrm{v})$.

The formation of the 4-CP photoproducts (benzoquinone (BQ) and hydroquinone (HQ)) and of 2,6 DMP photoproducts (2,6 dimethylbenzoquinone), were monitored against external standards.

\section{Results}

\subsection{Photophysical properties of the sensitizers}

The knowledge of the photophysical properties of the watersoluble porphyrins $\mathbf{1}, \mathbf{2}$ and $\mathbf{3}$, is important to establish the mechanism of photodegradation of phenols. We have measured the absorption and emission spectra of these sensitizers under different aqueous conditions, their triplet lifetimes in the presence and absence of oxygen in the presence of 4chlorophenol. Their singlet-oxygen and triplet quantum yields were also obtained.

It is well established that the concentration of TPPS and the $\mathrm{pH}$ of aqueous solutions alters its degree of protonation ${ }^{33}$ and of aggregation, and that these have strong effects on the absorption and emission spectra, $\Phi_{\mathrm{T}}$ and $\Phi_{\Delta} \cdot{ }^{34,35}$ Although the study of aggregate formation is not the main goal of this work, absorption spectra of all compounds were measured over a very wide range of concentrations $\left(10^{-4}\right.$ to $\left.10^{-8} \mathrm{M}\right)$ at $\mathrm{pH} 7$ and no modifications of the spectral shape or extinction coefficients were observed. We note, in particular, the absence of the bands at $489 \mathrm{~nm}$ and $710 \mathrm{~nm}$, typical of aggregates with TPPS. ${ }^{34}$

As shown in Fig. 1, absorption spectra of TDCPPS do show a red shift in the Soret band and transformation of the 4 free base $\mathrm{Q}$ bands to 2 on reducing the $\mathrm{pH}$, in agreement with the protonation of the porphyrin nitrogens in acid solution. In the above range of concentrations no modification in the absorptions spectra of TDCPPS were observed, even at $\mathrm{pH} 2$, this is probably due to the lower TDCPPS $\mathrm{p} K(1.4)$ than TPPS (4.7) and also due to the presence of bulky ortho-chloro groups in the phenyl rings of the porphyrin structure.

The fluorescence spectra of the sensitizers $\mathbf{1}, \mathbf{2}$ and $\mathbf{3}$ were measured in buffered aqueous solutions $\left(\mathrm{KH}_{2} \mathrm{PO}_{4}-\mathrm{NaOH}, \mathrm{pH}=\right.$ 7.4, absorbance 0.02 at $413 \mathrm{~nm}$ ), with excitation wavelength at $413 \mathrm{~nm}$, Fig. 2. The shape and positions of the emission bands 641 and $697 \mathrm{~nm}$ of porphyrin 1 are typical of the nonaggregated, free base porphyrins. ${ }^{33}$ With the corresponding metalloporphyrins, Zn(II)TDCPPS, 2, and Sn(IV)TDCPPS, 3, the shapes of the bands are significantly different from the free base porphyrin TDCPPS, $\mathbf{1}$, as predicted theoretically, ${ }^{36,37}$ with the intensity of the $(0,0)$ band lower than the $(0,1)$ 


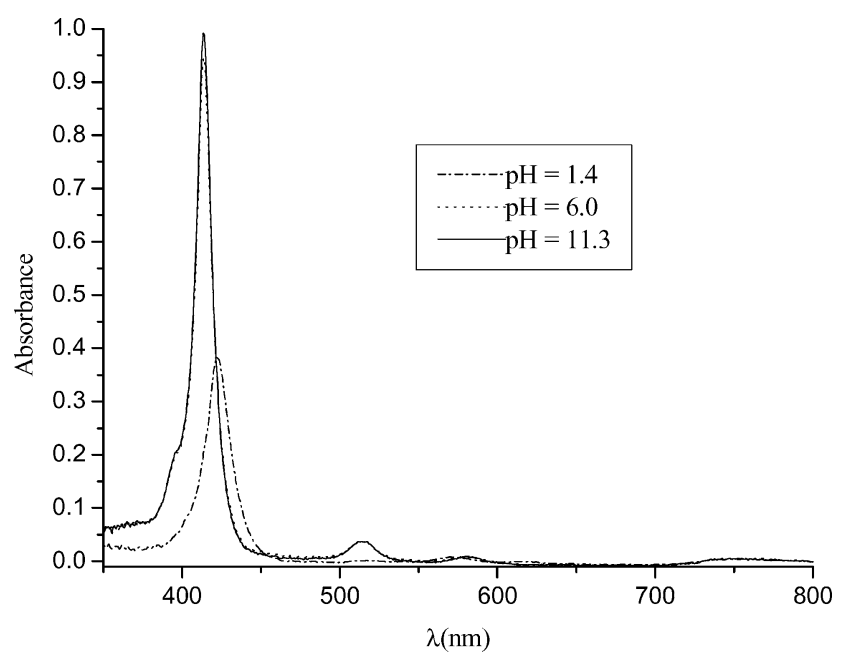

Fig. 1 Absorption spectra of TDCPPS in aqueous solutions $(1 \times$ $\left.10^{-5} \mathrm{M}\right)$ at $\mathrm{pH} 1.4,6.0$ and 11.3.

band in the metallated porphyrins, in agreement with the mirror-image relationship with the corresponding absorption spectra. Fluorescence excitation spectra were obtained for all the sensitizers and for TPPS, and the good agreement with the corresponding absorption spectra further confirms the purity of the samples.

Literature data on the fluorescence quantum yield $\left(\Phi_{\mathrm{F}}\right)$ of TPPS show a wide scatter, with values ranging from $\Phi_{\mathrm{F}}=$ $0.060 \pm 0.005$ to $0.16 .^{26,38,31}$ Such a variation, which may be a consequence of both $\mathrm{pH}$ effects and aggregation, has prompted us to make a reliable determination of the fluorescence quantum yield of TPPS using TPP in toluene $\left(\Phi_{\mathrm{F}}=0.11\right)^{26}$ as standard. The fluorescence quantum yield of TPPS was obtained by comparison between the integrated emission spectra of TPPS and the reference solution, after correcting for differences in the absorbance of the solutions and refractive index of the solvents. We obtained $\Phi_{\mathrm{F}}=0.054 \pm 0.005$, in very good agreement with Braslavsky and Gensch $^{38}$ who used tetrapropylporphycene in toluene as standard. It is worth noting that some of the other reported $\Phi_{\mathrm{F}}$ values are not accompanied by the description of the specific conditions of the experiment, such as $\mathrm{pH}$ and buffer, which may have significant effects on quantum yields, and it is important to emphasize that we observed significant differences in the emission intensity of TPPS as a function of properties of the solution. For example, we observed rather disperse values when we adjust the $\mathrm{pH}$ to 7 by adding few drops of a concentrated solution of $\mathrm{NaOH}$, while when the $\mathrm{pH}$ was adjusted with $\mathrm{NaHCO}_{3}$, a total quenching of the fluorescence was observed. With the phosphate buffer system mentioned above, we obtained reproducible fluorescence quantum yields

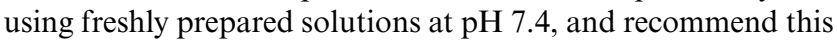
to be used as standard for this compound.

This TPPS ( $\left.c a .10^{-7} \mathrm{M}\right)$ solution buffered at $\mathrm{pH} 7.4$, was used as the reference for the determination of the fluorescence quantum yields of $\mathbf{1}, \mathbf{2}$ and $\mathbf{3}$ in aqueous solutions and the data are presented in Table 1. Although there is a significant difference between $\Phi_{\mathrm{F}}$ for TPPS and the corresponding $o$-chlorinated porphyrin, TDCPPS, $\mathbf{1}$, the central metal did not have any significant effect on. This is consistent with photophysical measurements on other $o$-halogenated porphyrins, where $\Phi_{\mathrm{F}}$ was found to decrease in the presence of halogen atoms in the $o$-positions of the phenyl ring, but was rather insensitive to the effect of the central metal ${ }^{20}$ reflecting the importance of throughspace interactions on the heavy atom effect.

The triplet-triplet absorption spectra of the sensitizers were obtained by laser flash photolysis, and show a common band with a maximum at $460 \mathrm{~nm}$, typical of porphyrinic compounds, Fig. 3. No other transient species were observed.
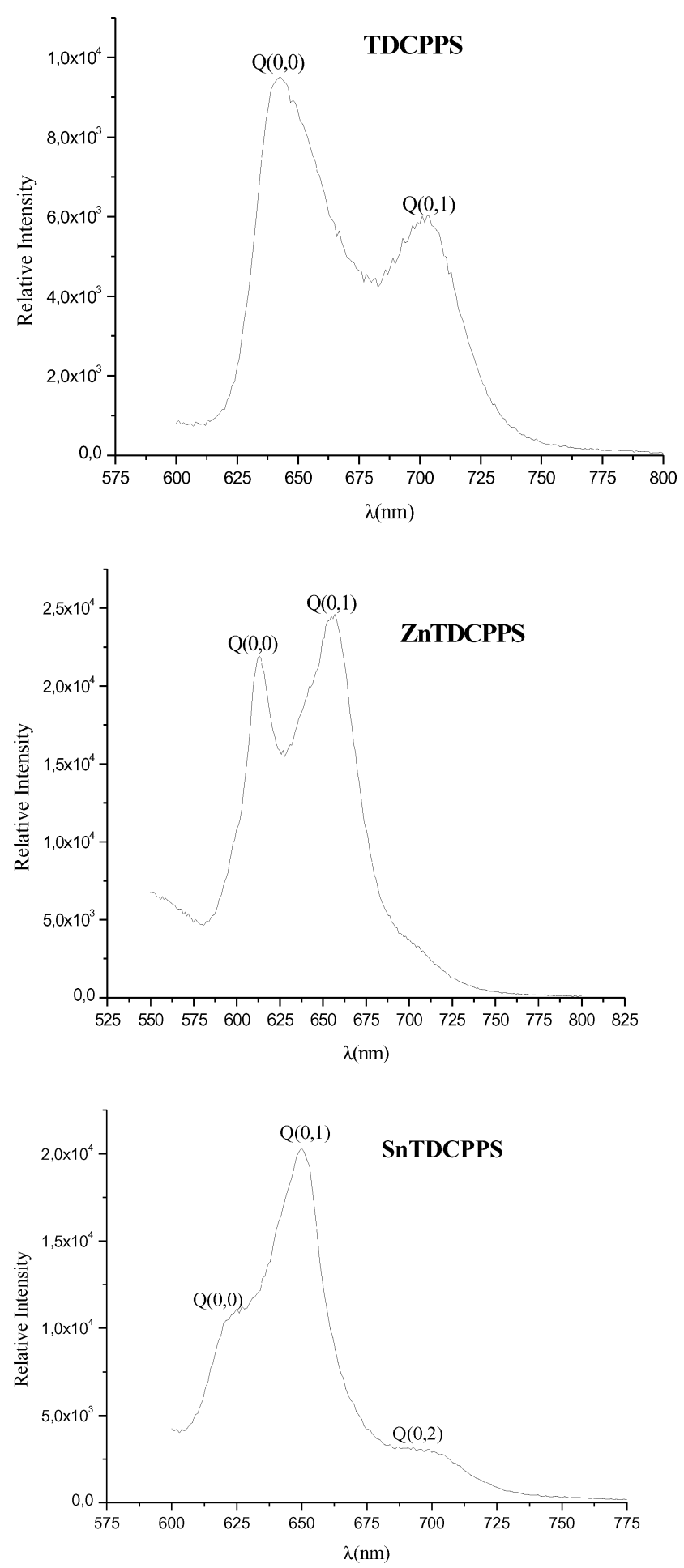

Fig. 2 Fluorescence spectra of sensitizers TDCPSS, ZnTDCPPS, SnTDCPPS in aqueous solutions.

The triplet-state lifetimes of porphyrin $\mathbf{1}$ and metalloporphyrins 2 and $\mathbf{3}$ in aqueous solutions, $\mathrm{pH}=7.4$ excited at $355 \mathrm{~nm}$ $\left(A_{355}=0.20\right)$ were measured at $460 \mathrm{~nm}$ under air and argon atmospheres, and from these the bimolecular rate constants $\left(k_{\mathrm{q}}\right)$ for the quenching of the triplet states of sensitizers by molecular oxygen $\left({ }^{3} \mathrm{O}_{2}\right)$ were calculated using the concentration of oxygen in water $\left(2.9 \times 10^{-4} \mathrm{M}\right){ }^{27}$

$$
k_{\mathrm{q}}=\left(1 / \tau \mathrm{O}_{2}-1 / \tau \mathrm{N}_{2}\right) /\left[\mathrm{O}_{2}\right]
$$

Table 2 presents the values obtained for lifetimes and rate constants. Following the classical work of Porter and co-workers ${ }^{39}$ it is believed that when sufficiently exothermic triplet-triplet energy transfers to molecular oxygen occur, $k_{\mathrm{q}}$ 
Table 2 Triplet lifetimes in aerated and deaerated aqueous solutions, with respective oxygen quenching rate constants, triplet and singlet oxygen quantum yields

\begin{tabular}{|c|c|c|c|c|c|c|c|c|}
\hline Sensitizer & $\tau_{\mathrm{O}_{2}} / \mu \mathrm{s}$ & $\tau_{\mathrm{N}_{2}} / \mu \mathrm{s}$ & $k_{\mathrm{q}}\left(\mathrm{O}_{2}\right) / \mathrm{M}^{-1} \mathrm{~s}^{-1}$ & $\varepsilon^{*}{ }_{\mathrm{T}} / \mathrm{M}^{-1} \mathrm{~cm}^{-1}$ & $\phi_{\Delta}^{a}$ & $\phi_{\Delta}^{b}$ & $\phi_{\mathrm{T}}^{c}$ & $S_{\Delta}$ \\
\hline TDCPPS, 1 & $4.21 \pm 0.06$ & $397.4 \pm 3.5$ & $8.39 \times 10^{8}$ & $6.2 \times 10^{4}$ & $0.73 \pm 0.10$ & $0.76 \pm 0.11$ & 0.88 & 0.83 \\
\hline ZnTDCPPS, 2 & $7.93 \pm 0.09$ & $368.7 \pm 6.4$ & $4.41 \times 10^{8}$ & $6.5 \times 10^{4}$ & $0.51 \pm 0.07$ & $0.59 \pm 0.09$ & 0.92 & 0.55 \\
\hline SnTDCPPS, 3 & $10.46 \pm 0.09$ & $432.4 \pm 14.0$ & $3.33 \times 10^{8}$ & $6.2 \times 10^{4}$ & $0.51 \pm 0.12$ & $0.46 \pm 0.07$ & 0.83 & 0.61 \\
\hline
\end{tabular}

${ }^{a}$ Obtained in Coimbra using infrared photomultiplier as detector. ${ }^{b}$.Obtained in Daresbury using a germanium photodiode. ${ }^{c}$ Estimated error $15 \%$.

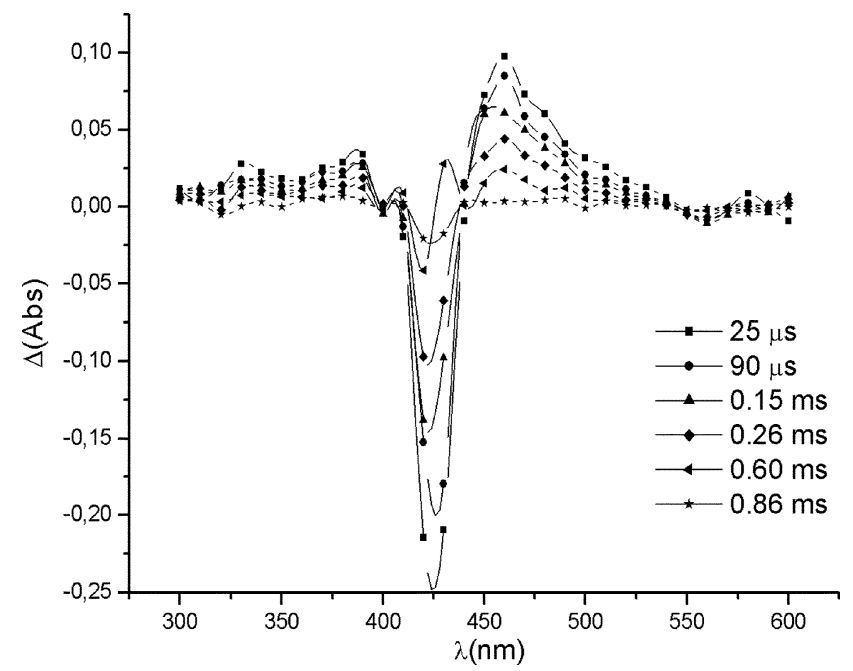

Fig. 3 Transient absorption spectra observed following laser flash photolysis at $355 \mathrm{~nm}$ of an argon-saturated solution of sensitizer $\mathbf{2}$ in water.

attains the statistical limit of one ninth of the diffusion rate constant $\left(k_{\text {diff }}\right)$.

$$
\text { Sens }\left(\mathrm{T}_{1}\right)+{ }^{3} \mathrm{O}_{2} \rightarrow \operatorname{Sens}\left(\mathrm{S}_{0}\right)+{ }^{1} \mathrm{O}_{2}
$$

Taking $k_{\text {diff }}=9.8 \times 10^{9} \mathrm{M}^{-1} \mathrm{~s}^{-1}$ in water, the quenching rate constants obtained in this work are lower than expected for this mechanism $\left(1.0 \times 10^{9} \mathrm{M}^{-1} \mathrm{~s}^{-1}\right)$. A similar effect has already been observed for the quenching of $o$-chlorinated porphyrins, chlorins and bacterichlorins by oxygen in toluene solutions. ${ }^{19,40,41}$ The oxygen quenching rate constants measured for the chlorosulfonated porphyrins in aqueous solution in this work are in very good agreement with the rates measured for the analogous chlorinated porphyrins in toluene ${ }^{19,40} k_{\mathrm{q}}$ (TDCPPS $)=8.4 \times 10^{8}$ vs. $k_{\mathrm{q}}(\mathrm{TDCPP})=8.6 \times 10^{8} \mathrm{M}^{-1} \mathrm{~s}^{-1}$ and $k_{\mathrm{q}}(\mathrm{ZnTDCPPS})=$ $4.4 \times 10^{8}$ vs. $k_{\mathrm{q}}(\mathrm{ZnTDCPP})=6.2 \times 10^{8} \mathrm{M}^{-1} \mathrm{~s}^{-1}$, which is consistent with the expectation that the sulfonic groups do not contribute to the Franck-Condon factors associated with energy transfer. The triplet state quenching mechanism was further explored using room-temperature, time-resolved singlet oxygen phosphorescence measurements, as described below.

\subsection{Singlet oxygen emission}

Singlet oxygen quantum yields following laser excitation of sensitizer solutions can be obtained from the comparison of singlet oxygen phosphorescence intensity at $1270 \mathrm{~nm}$ with that of an optically matched reference sensitizer. For TPPS in water at $\mathrm{pH} 7$, the literature $\Phi_{\Delta}$ values, $0.62-0.64$, are identical within the experimental error, ${ }^{31,35,42-44}$ and we have used the value ${ }^{31}$ of 0.64 for this sensitizer in deuterated water at $\mathrm{pH}$ 7.4. Two independent detection systems were used, with data from that in Coimbra using an infrared photomultiplier, which had not previously been verified for this type of measurements, compared with those of a well-established set-up using a germanium diode. In the studies using the infrared sensitive photomultiplier, the decays of the singlet oxygen emissions were measured at $1270 \mathrm{~nm}$ with the reference and with our sensitizers, with matched absorbances at the excitation wavelength, and were extrapolated to time-zero at a given laser intensity.

Different laser intensities were employed and the quantum yields were obtained from the ratios of the slopes obtained with different sensitizers and TPPS as standard. The singlet oxygen quantum yields of sensitizers $\mathbf{1}, \mathbf{2}$ and $\mathbf{3}$ in $\mathrm{D}_{2} \mathrm{O}$ solutions are reported in Table 2.

Measurements were also made using a germanium diode detector, and are also given in Table 2. Reasonable agreement is observed between results using the two detectors, validating the infrared photomultiplier system. It can be noted that absolute uncertainties in measurements of singlet oxygen quantum yields range typically between $\pm 7 \%$ and $\pm 15 \%,{ }^{42}$ and the differences between our results using the independent set-ups are well within these limits.

\subsection{Phenol photodegradation}

Photodegradation kinetics of 4-CP and 2,6-dimethylphenol were studied with sensitizers $\mathbf{1}, \mathbf{2}$ and $\mathbf{3}$ by following the changes in the absorption spectra with the irradiation time or HPLC. The absorption spectrum of 4-CP is in the wavelength range between 240 and $300 \mathrm{~nm}$ with a maximum at $280 \mathrm{~nm}$, and during irradiation, the most important changes were observed in this region, with a significant decrease in the band at $280 \mathrm{~nm}$ and a concomitant increase in absorption in the region between 240 $265 \mathrm{~nm}$.

The HPLC analysis against standards of the reaction mixture of all the systems after $7 \mathrm{~h}$ of irradiation indicated that the main photoproducts were $p$-benzoquinone and $p$-hydroquinone with 4-CP and mainly 2,6-dimethylbenzoquinone (2,6-DBQ) with 2,6-DMP. With longer irradiation time several secondary photoproducts were formed, but these have not yet been identified.

Despite of the overlapping of absorption spectrum of 4$\mathrm{CP}$ and the main photoproducts bands, $p$-benzoquinone $(\lambda=$ $245 \mathrm{~nm})$ and $p$-hydroquinone $(\lambda=288 \mathrm{~nm})$, it was possible to carry out a spectral deconvolution in order to separate the absorbances of the reagents and the photoproducts as described in ref. 45. This was done with the program SPECPEAK, version 2.0 assuming Gaussian band shapes. The most interesting Gaussian bands from the point of view of their physical meaning are at 245, 280, and $286 \mathrm{~nm}$. As anticipated, the height of the Gaussian band at $280 \mathrm{~nm}$ (attributed to 4-CP absorption) decreases exponentially with the irradiation time while those of $p$-benzoquinone and $p$-hydroquinone (measured at 245 and $286 \mathrm{~nm}$ respectively) increase. The exponential decay of the Gaussian band at $280 \mathrm{~nm}$ for the system 4-CP $\left(5 \times 10^{-4} \mathrm{M}\right)$ using TDCPPS $\left(10^{-4} \mathrm{M}\right)$ as sensitizer, follows first order kinetics. The calculated rate constants for all the systems studied, using different sensitizers, are collected in Table 3 .

To corroborate these calculations, the same deconvolution treatment was done for the system 4-CP sensitized by FeTDCPPS and the kinetic constant $k=1.2 \times 10^{-4} \mathrm{~s}^{-1}$ was obtained. This is in agreement with the value $\left(k=9.5 \times 10^{-5} \mathrm{~s}^{-1}\right)$ obtained by HPLC analysis. ${ }^{17}$

In order to design more efficient photosensitizers for the oxidation of phenols, it is important to understand the mechanism involved in the reactions described above. Four different 
Table 3 Kinetic constants for sensitized photodegradation reaction of 4-CP obtained from the exponential decrease of Gaussian band at $280 \mathrm{~nm}$ deconvoluted as described in ref. 45

\begin{tabular}{ll}
\hline Porphyrin & $k(4-\mathrm{CP}) / \mathrm{s}^{-1}$ \\
\hline TDCPPS, 1 & $2.7 \times 10^{-5}$ \\
ZnTDCPPS, 2 & $3.7 \times 10^{-4}$ \\
SnTDCPPS, 3 & $1.3 \times 10^{-3}$
\end{tabular}

Table 4 Quenching constants of triplet state of sensitizers 1, 2 and 3 by 4-CP in argon saturated aqueous solutions

\begin{tabular}{ll}
\hline Sensitizer & $k_{\mathrm{q}}(4-\mathrm{CP}) / \mathrm{M}^{-1} \mathrm{~s}^{-1}$ \\
\hline TDCPPS, 1 & $\leq 10^{6}$ \\
ZnTDCPPS, 2 & $1.9 \times 10^{7}$ \\
SnTDCPPS, 3 & $2.2 \times 10^{7}$ \\
\hline
\end{tabular}

processes have been followed: (i) singlet oxygen formation with all the photosensitizers 1, 2 and 3, Table 2; (ii) laser flash photolysis studies of sensitizer triplet state decay in the presence and absence of oxygen, Table 2; (iii) laser flash photolysis of the sensitizer triplet states in the presence of phenols, Table 4; (iv) photolysis of 4-CP using sensitizer 1, with radical and oxygen singlet traps, Fig. 4.

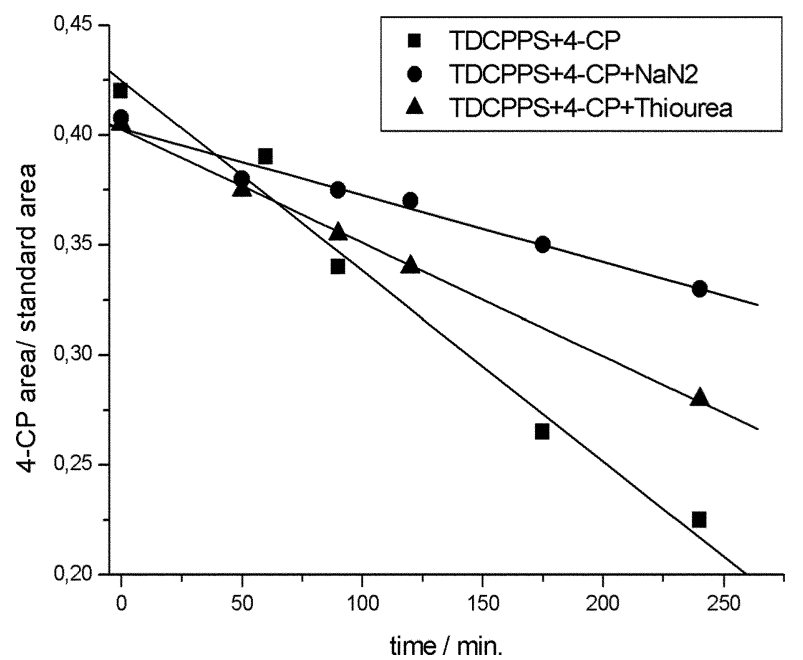

Fig. 4 HPLC, kinetic studies of TDCPPS sensitized photodegradation of 4-CP in aqueous solution in the presence of sodium azide and thiourea using 2,4-dichlorophenol as external standard.

To evaluate the quenching of the triplet state of the sensitizers by phenols, 4-chlorophenol was taken as a model compound, and flash photolysis experiments were carried out with excitation at $355 \mathrm{~nm}$ of aqueous solutions deaerated with argon with different 4-CP concentrations $\left(2.1-8.4 \times 10^{-3} \mathrm{M}\right)$. The relevant second order quenching rate constants are presented in Table 4.

A significant difference was observed between rate constants for reaction of 4-CP with the free base porphyrin and with the metalloporphyrins, indicating the importance of the central metal on the mechanism of photodegradation. The expected reaction involves electron transfer from chlorophenol to the excited porphyrin, as suggested for 4-CP and FeTDCPPS by the observation of dimeric products. ${ }^{17}$ The above differences probably reflect variations in the oxidation potential of the excited triplet state of the porphyrins. Since the triplet state of TDCPPS, 1, is not significantly quenched by 4-CP, this sensitizer was selected to study the effect of the singlet oxygen scavenger sodium azide and the radical trap thiourea on the photodegradation rate. Two groups of experiments were carried out on aerated aqueous solutions of TDCPPS $\left(10^{-4} \mathrm{M}\right)$ and 4$\mathrm{CP}\left(5 \times 10^{-4} \mathrm{M}\right)$ irradiated at $350 \mathrm{~nm}$. The first was made in the presence of sodium azide $\left(10^{-3} \mathrm{M}\right)$, while for the second thiourea $\left(10^{-3} \mathrm{M}\right)$ was added. Aliquots from the irradiated solutions were analysed following various times of irradiation by HPLC. Data are compared with those under similar conditions in the absence of scavengers. In all cases the decrease of the concentration of 4-CP follows good first order kinetics, with rate constants $k($ TDCPPS $)=8.47 \times 10^{-4} \mathrm{~s}^{-1}, k\left(\mathrm{NaN}_{3}\right)=2.44 \times 10^{-4} \mathrm{~s}^{-1}$, $k$ (thiourea $)=4.60 \times 10^{-4} \mathrm{~s}^{-1}$.

From the overall results, and the fact that the rates are slower in the presence of either scavenger when compared to the system without scavenger, it is possible to conclude that both Type I and Type II mechanisms are involved. However, from the relative rate constants in the presence of $\mathrm{NaN}_{3}$ and thiourea (singlet oxygen and radical trap respectively) with sensitizer $\mathbf{1}$, it seems probable that the main mechanism involves singlet oxygen. This is in agreement with kinetic data on triplet quenching by 4$\mathrm{CP}$, Table 4, and singlet oxygen quantum yields, Table 2 . In contrast, with sensitizers $\mathbf{2}$ and $\mathbf{3}$ the main mechanism seems to involve electron transfer, since higher rate constants of the triplet quenching by 4-CP are observed, which is in agreement with the lower singlet oxygen quantum yield efficiency $\left(S_{\Delta}\right.$, Table 2$)$.

As in our previous study with FeTDCPPS, ${ }^{17}$ the two mechanisms occur in parallel, but their relative importance is strongly dependent upon the particular porphyrin used. The fact that with sensitizers $\mathbf{2}$ and $\mathbf{3}$ the direct reaction between the triplet state and 4-CP is more efficient than with the free base (Tables 2 and 4 ) is in agreement with the lower triplet and singlet oxygen quantum yield observed for these metalloporphyrins.

The quantum yields of photodegradation of 2,6-DMP were measured with sensitizers $\mathbf{1}, \mathbf{2}$ and $\mathbf{3}$ under continuous excitation at $415 \mathrm{~nm}$, Table 5 .

In all the cases, the role played by molecular oxygen in the degradation mechanism of 2,6-DMP is highlighted by the fact that the quantum yield of 2,6-DMP disappearance decreases when oxygen free solutions were used. Such an observation could be due to the formation of singlet oxygen as already shown for 4-CP. This result was further confirmed by using $\mathrm{NaN}_{3}$ as singlet oxygen scavenger. However, it is clear from the facts that substantial degradation of 2,6-DMP was also observed in deaerated solution, and that the quantum yields of this are comparable to those in the presence of azide ion that two pathways in parallel are involved in the photodegradation: singlet oxygen and electron transfer process.

It is interesting to note that 2,6-dimethylbenzoquinone (2,6DBQ) was the main product observed in all systems. However, this only accounted for roughly $50 \%$ of 2,6 -DMP conversion. As previously reported on degradation via radical processes, ${ }^{5,17}$ the formation of dimeric and oligomeric products may explain these observations.

Table 5 Quantum yields for disappearance of 2,6-DMP $\left(1 \times 10^{-3} \mathrm{M}\right)$ from aqueous solutions in the presence of sensitizers $\mathbf{1}$, 2 and $\mathbf{3}$ under different experimental conditions. These were determined at about $10 \%$ conversion of $2,6-\mathrm{DMP}$

\begin{tabular}{lrrr}
\hline Conditions & TDCPPS, 1 & ZnTDCPPS, 2 \\
\hline Aerated solution & $1.5 \times 10^{-2}$ & $8.0 \times 10^{-2}$ & $3.8 \times 10^{-2}$ \\
Deaerated solution & $3.5 \times 10^{-3}$ & $2.5 \times 10^{-2}$ & $1.5 \times 10^{-2}$ \\
Oxygenated solution & $1.3 \times 10^{-2}$ & $8.5 \times 10^{-2}$ & $4.0 \times 10^{-2}$ \\
Aerated solution in the presence of $\mathrm{NaN}_{3}\left(1.0 \times 10^{-3} \mathrm{M}\right)$ & $3.4 \times 10^{-3}$ & $1.0 \times 10^{-2}$ \\
\hline
\end{tabular}




\section{Conclusions}

The results of this study show that 5,10,15,20-tetrakis(2,6dichloro-3-sulfophenyl)porphyrin and its tin, and zinc complexes are efficient photosensitizers for the degradation of phenols in aqueous solutions. In all cases, the porphyrins sensitize singlet oxygen formation, leading to the possibility of a Type II degradation mechanism, probably proceeding via $2+4$ cycloaddition to form the endoperoxide, followed by formation of $p$-benzoquinone and hydroquinone. Some hydroquinone may also be formed on direct photolysis of benzoquinone. ${ }^{46}$ It is possible that there is also formation of some hydroperoxide, and we note that metallopthalocyanines photosensitize the breakdown of these to form hydroxyl, alkoxyl or peroxyl free radicals. ${ }^{47}$ This is also likely to be the case with these metalloporphyrins.

However, the flash photolysis results reported here and in a previous study ${ }^{17}$ show this occurs in parallel with electron transfer from chlorophenols to metalloporphyrins, to produce phenoxyl radicals. This will lead to formation of benzoquinone derivatives and oligomeric species. The relative importance of the two parallel pathways is strongly dependent on the porphyrin used.

In contrast to other water soluble porphyrins, these chlorosubstituted derivatives show little tendency to aggregate under the conditions studied and are excellent candidates for sensitizing photodegradation of phenols with visible light. This work is being extended to a study of the photodegradation under environmental conditions using immobilized porphyrins.

\section{Acknowledgements}

The authors thank FCT, FEDER, POCTI, the Universidad de Burgos and GRICES-CNRS for financial support. Singlet oxygen measurements experiments at the Free Radical Research Facility in the Synchrotron Radiation Department of the CLRC Daresbury Laboratory, Warrington, UK, were carried out with the support of the European Commission through the "Improving Human Potential" Transnational Access to Major Research Infrastructures Contract HPRI-CT-2002-00183.

\section{References}

1 M. Sarakha, M. Bolte and H. D. Burrows, Electron-transfer oxidation of chlorophenols by uranyl ion excited state in aqueous solution. Steady-state and nanosecond flash photolysis studies, J. Phys. Chem. A, 2000, 104, 3142-3149.

2 J. C. D'Oliveira, G. Al-Sayyed and P. Pichat, Photodegradation of 2-chlorophenol and 3-chlorophenol in $\mathrm{TiO}_{2}$ aqueous suspensions, Environ. Sci. Technol, 1990, 24, 990-996.

3 M. J. Kochany and J. R. Bolton, Mechanism of photodegradation of aqueous organic pollutants. 2. Measurement of the primary rate constants for reaction of $\mathrm{OH}$ radicals with benzene and some halobenzenes using and EPR spin-trapping method following the photolysis of $\mathrm{H}_{2} \mathrm{O}_{2}$, Environ. Sci. Technol., 1992, 26, 262-265.

4 M. Sarakha, H. D. Burrows and M. Bolte, Selective oxidation of meta- and para-phenylphenol photosensitized by $\left[\mathrm{Co}\left(\mathrm{NH}_{35} \mathrm{~N}_{3}\right]^{2+}\right.$ in aqueous solution, J. Photochem. Photobiol., A, 1996, 97, 81-86.

5 M. Sarakha, M. Bolte and H. D Burrows, The photo-oxidation of 2,6dimethylphenol and monophenylphenols by uranyl ion in aqueous solution, J. Photochem. Photobiol., A, 1997, 107, 101-106.

6 M. Nowakowska and M. Kepczynski, Polymeric photosensitizers2. Photosensitized oxidation of phenol in aqueous solution, J. Photochem. Photobiol., A, 1998, 116, 251-256.

7 O. Legrini, E. Oliveros and A. M. Braun, Photochemical processes for water treatment, Chem. Rev., 1993, 93, 671-698.

8 P. Boule, C. Richard, K. David-Oudjehani and G. Grabner, Photochemical behaviour of halophenols in aqueous solution, Proc. Indian Acad. Sci. Chem. Sci., 1997, 109, 509-519.

9 Y. I. Skurlatov, L. S. Ernestova, E. V. Vichutinskaya, D. P. Samsonov, I. V. Semenova, I. Y. Rodko, V. O. Shvidky, R. I. Pervunina and T. J Kemp, Photochemical transformation of polychlorinated phenols, J. Photochem. Photobiol., A, 1997, 107, 207-213.

10 H. D. Burrows, L. S. Ernestov, T. J. Kemp, Y. I. Skurlatov, A. P. Purmal and A. N. Yermakov, Kinetics and mechanism of photodegradation of chlorophenols, Prog. React. Kinet., 1998, 23, 145-207.

11 P. G. Tratnyek and J. Hoigné, Oxidation of substituted phenols in the environment - a QSAR analysis of rate constants for reaction with singlet oxygen, Environ. Sci. Technol., 1991, 25, 1596-1604.

12 N. A. Garcia, Singlet-molecular-oxygen mediated photodegradation of aquatic phenolic pollutants, A kinetic and mechanistic overview, J. Photochem. Photobiol., B, 1994, 22, 185-196.

13 J. A. Rosso, S. Criado, S. G. Bertolotti, P. E. Allegretti, J. Furlong, N. A. Garcia, M. C. Gonzalez and D. O. Mártire, Photochem. Photobiol. Sci., 2003, 2, 882-887.

14 M. Gouterman, Optical spectra and electronic structure of porphyrins and related rings, in The Porphyrins Vol. III Physical Chemistry, Part A, ed. D. Dolphin, Academic Press, New York, 1978, pp. 1-156.

15 K. Ozoemena, N. Kuznetsova and T. Nyokong, Photosensitized transformation of 4-chlorophenol in the presence of aggregated and non-aggregated metallophthalocyanines, J. Photochem. Photobiol., A, 2001, 139, 217-224.

16 G. Lente and J. H. Espenson, Photoaccelerated oxidation of chlorinated phenols, Chem. Commun., 2003, 1162-1163.

17 E. Silva, M. M. Pereira, H. D. Burrows, M. E. Azenha, M. Sarakha and M. Bolte, Photooxidation of 4-chlorophenol sensitised by iron meso-tetrakis(2,6-dichloro-3-sulfophenyl)porphyrin in aqueous solution, Photochem. Photobiol. Sci., 2004, 3, 200-204.

18 C. Tanielian, R. Mechin, R. Seghrouchini and C. Schweitzer, Mechanistic and kinetics aspects of photosensitization in the presence of oxygen, Photochem. Photobiol., 2000, 71, 12-19.

19 M. Pineiro, L. Carvalho, M. M. Pereira, A.M. D. R. Gonsalves, L. G. Arnaut and S. J. Formosinho, Photoacoustic measurements of porphyrin triplet-state quantum yields and singlet-oxygen efficiencies, Chem.-Eur. J., 1998, 4, 2299-2307.

20 E. G. Azenha, A. C. Serra, M. Pineiro, M. M. Pereira, J. S. de Melo, L. G. Arnaut, S. J. Formosinho and A. M. D. R. Gonsalves, Heavyatom effects on metalloporphyrins and polyhalogenated porphyrins, Chem. Phys., 2002, 280, 177-190.

21 M. C. DeRosa and R. J. Crutchley, Photosensitized singlet oxygen and its applications, Coord. Chem. Rev., 2002, 233, 351-371.

22 D. Murtinho, M. Pineiro, M. M. Pereira, A. M. D. R. Gonsalves, L. G. Arnaut, M. G. Miguel and H. D. Burrows, Novel porphyrins and a chlorin as efficient singlet oxygen sensitizers for photooxidation of naphthols and phenols to quinones, J. Chem. Soc., Perkin Trans. 2, 2000, 2441-2447.

23 A. M. D. R. Gonsalves, R. A. W. Johnstone, M. M. Pereira, A. M. P. deSantAna, A. C. Serra, A. J. F. N. Sobral and P. A. Stocks, New procedures for the synthesis and analysis of 5,10,15,20tetrakis(sulfophenyl)porphyrins and derivatives through chlorosulfonation, Heterocycles, 1996, 43, 829-838.

24 A. D. Adler, F. R. Longo, F. Kampas and J. Kim, On preparation of metalloporphyrins, J. Inorg. Nucl. Chem., 1970, 32, 2443-2445.

25 D. G. Whitten, J. C. Yau and F. A. Carroll, Photochemistry and oxidation-reduction reactions of tin porphyrins, J. Am. Chem. Soc., 1971, 93, 2291-2296.

26 W. A. Lee, M. Graetzel and K. Kalyanasundaram, Anomalous ortho effects in sterically hindered porphyrins: tetrakis(2,6dimethylphenyl)porphyrin and its sulfonate derivative, Chem. Phys. Lett., 1984, 107, 308-313.

27 S. L. Murov, I. Carmichael, G. L. Hug, Handbook of Photochemistry, Marcel Dekker, New York, 1993

28 J. P. Keene, D. Kessel, E. J. Land, R. W. Redmond and T. G. Truscott, Direct detection of singlet oxygen sensitized by hematoporphyrin and related compounds, Photochem. Photobiol., 1986, 43, 117-120.

29 S. Navaratnam, I. Hamblet and H. H. Tonnesen, Photoreactivity of biologically active compounds. XVI. Formation and reactivity of free radicals in mefloquine, J. Photochem. Photobiol., B, 2000, 56, 25-38.

30 H. D. Burrows, J. S. de Melo, C. Serpa, L. G. Arnaut, A. P. Monkman, I. Hamblett and $S$. Navaratnam, $S_{1}$ to $T_{1}$ intersystem crossing in $\pi$-conjugated organic polymers, J. Chem. Phys., 2001, 115, 96019606.

31 J. Davila and A. Harriman, Phototosensitized-oxidation of biomaterials and related model compounds, Photochem. Photobiol., 1989, 50, 29-35.

32 J. G. Calvert and J. M. Pitts, Photochemistry, John Wiley and Sons, New York, 1996, pp. 783-786.

33 P. J. Gonçalves, L. De Boni, N. M. Barbosa Neto, J. J. Rodrigues, Jr., S. C. Zílio and I. E. Borissevitch, Effect of protonation on the photophysical properties of meso-tetra(sulfonatophenyl)porphyrin, Chem. Phys. Lett., 2005, 407, 236-241.

34 D. L. Akins, H. R. Zhu and C. Guo, Aggregation of tetraarylsubstituted porphyrins in homogeneous solution, J. Phys. Chem., 1996, 100, 5420-5425. 
35 T. Gensch, C. Viappiani and S. E. Braslavsky, Structural Volume Changes upon photoexcitation of porphyrins: role of the nitrogen-water interactions, J. Am. Chem. Soc., 1999, 121, 1057310582.

36 M. Gouterman, Spectra of porphyrins, J. Mol. Spectrosc., 1961, 6, $138-163$.

37 P. G. Seybold and M. Gouterman, Porphyrins, 13: Fluorescence spectra and quantum yields, J. Mol. Spectrosc., 1969, 31, 1-13.

38 T. Gensch and S. E. Braslavsky, Volume changes related to triplet formation of water-soluble porphyrins. A laser-induced optoacoustic spectroscopy (LIOAS) study, J. Phys. Chem. B, 1997, 101, 101-108.

39 O. L. Gijzema, F. Kaufman and G. Porter, Oxygen quenching of aromatic triplet-states in solution. Part 1, J. Chem. Soc., Faraday Trans. 2, 1973, 69, 708-720.

40 M. Pineiro, M. M. Pereira, A. M. D. R. Gonsalves, L. G. Arnaut and S. J. Formosinho, Singlet oxygen quantum yields from halogenated chlorins: potential new photodynamic therapy agents, J. Photochem. Photobiol., A, 2001, 138, 147-157.

41 M. Pineiro, A. M. D. R. Gonsalves, M. M. Pereira, S. J. Formosinho and L. G. Arnaut, New halogenated phenylbacteriochlorins and their efficiency in singlet-oxygen sensitization, J. Phys. Chem. A, 2002, 106, 3787-3795.

42 R. Schmidt, C. Tanielian, R. Dunsbach and C. Wolff, Phenalenone, a universal reference compound for the determination of quantum yields of singlet oxygen $\mathrm{O}_{2}{ }^{1} \Delta_{\mathrm{g}}$ ) sensitization, J. Photochem. Photobiol., A, 1994, 79, 11-17.

43 C. Tanielian, C. Wolff and M. Esch, Singlet oxygen production in water: aggregation and charge-transfer effects, J. Phys. Chem, 1996, 100, 6555-6560

44 J. Davila and A. Harriman, Photoreactions of macrocyclic dyes bound to human-serum albumin, Photochem. Photobiol., 1990, 51, 9.

45 M. C. Aragoni, M. Arca, G. Crisponi and V. M. Nurchi, Simultaneous decomposition of several spectra into the constituent Gaussian peaks, Anal. Chim. Acta, 1995, 316, 195-204.

$46 \mathrm{H}$. Gorner, Photoprocesses of $p$-benzoquinones in aqueous solution, J. Phys. Chem. A, 2003, 107, 11587-11595.

47 T. G. Gantchev, W. M. Sharman and J. E. van Lier, Metallophthalocyanines photosensitize the breakdown of (hydro)peroxides in solution to yield hydroxyl or alkoxyl and peroxyl free radicals via different interaction pathways, J. Photochem. Photobiol., 2003, 77, 469-479.

48 R. V. Bensson, E. J. Land, T. G. Truscott, Excited states and free radicals in biology and medicine, Oxford University Press, Oxford, 1993, pp. 76-82.

49 G. S. Nahor, J. Rabani and F. Grieser, Properties of excited tetrakis(sulfonatophenyl)porphyrin in aqueous solution. Photoredox reactions with quenchers, J. Phys. Chem., 1981, 85, 697-702. 